\title{
TECHNICAL EFFICIENCY OF CHILI FARMS IN THAILAND: A METAFRONTIER APPROACH
}

\author{
Wirat Krasachat \\ King Mongkut's Institute of Technology Ladkrabng
}

\begin{abstract}
The primary purpose of this study is to measure and investigate farm practices affecting technical efficiencies of small chili farms in Thailand. In this study, the sample includes good agricultural practice (GAP) farms as well as conventional farms in 2012 crop year. These farms grow chili in either dry or rainy season. Similar to agricultural efficiency studies, this study includes one output and four inputs. In addition, the sample is divided into two groups by season. The stochastic frontier is applied to construct GAP and conventional farm frontiers and a pooled data set for comparison by using the concept of a metafrontier. Technical efficiencies for chili farms operating under different technologies were estimated. The empirical results suggest two important findings. First, GAP has different impacts on technical efficiency in Thai chili production in different farms. Second, there is confirmation that the difference in chili growing season also has influenced the technical efficiency of chili farms. The findings would provide motivation for nonadopting GAP farms to adopt GAP and for both groups to further improve their efficiency. Chili production through GAP adopting farms would likely meet quality standards acceptable by manufacturing purchasers and importers, furthering their well-being and supporting Thailand 4.0 goal.
\end{abstract}

Keywords: economics; good agricultural practices; metafrontier; stochastic frontier; technology adoption 